\title{
On the Long-term Behavior of Wind-Wave Climatology over the West Region of Scotland, UK
}

\author{
Tarek M. El-Geziry \\ Laboratory of Physical Oceanography, Division of Marine Environment, National \\ Institute of Oceanography and Fisheries, Alexandria, Egypt \\ tarekelgeziry@yahoo.com
}

\begin{abstract}
Using 38 years (January 1973-December 2010) of hourly wind records, the present paper aims at drawing the possible long-term trends of winds and ten surface wave parameters over the west region of Scotland, using the quadratic regression approach.

Four dominant wind components were determined: the southern, the western, the south-western and the north-western. Two opposite groups of oscillations were proven: one for the southern groups and one for the western groups.
\end{abstract}

The examined wave parameters were: the wave frequency, the wave angular frequency, the peak angular frequency, the wave spectral density, the significant wave height, the peak period, both the peak and group velocities and lastly the wave energy and the wave power.

Results revealed that every examined parameter tended to have a cyclic behaviour except the wave spectral density, which appeared to be linearly decreasing. All wave frequencies were in an inverse correlation to the mean monthly wind speed. All other wave parameters appeared to be highly correlated to the mean monthly wind speed with correlation factors exceeding 0.95 except the wave power, which had a correlation factor of 0.89 .

In conclusion, the general behaviours of the dominant wind components over the west region of Scotland, and of the different wave parameters tend to be cyclic. A longer time series, than that presently used, will be advantageous in order to strengthen this outcome with more robust investigation. This concluded cyclic behaviour may positively have impact on the engineering work within the wave energy resource off the western coasts of Scotland.

Keywords - Scotland, Anomaly, Wind, Wave, Quadratic regression, Cycles.

\section{INTRODUCTION}

It is well-known that air masses intrusion or replacement over any area or basin is the primary mechanism connecting atmospheric and oceanic characteristics through the transfer of heat, moisture and momentum at the sea surface (El- Geziry et al. 2013). Ocean waves are produced by the movement of these air masses (winds) over the sea surface. The faster the wind, the longer the wind blows, and the bigger the area over which the wind blows, the bigger the generated waves. Wave energy, i.e. energy of ocean surface waves, is created by the drag of winds over the sea (Mollison 1994).

The west region of Scotland (Fig. 1), extending along the Atlantic Ocean, tends to have one of the strongest and, meanwhile, steadiest wind system all over the world. The region is also believed to be one of the worldwide vital renewable energy resource with its surface wave characteristics. Geographically, the west region of Scotland covers the western half of both the Central Lowlands and Southern Uplands of Scotland. This comprises Kintyre, Strathclyde, Galloway and Dumfries. The region also includes the Isles of Tiree, Mull, Arran and Jura.

Factually, the examination of the long-term behaviour of wind at a given site is considered a clue to understand changes in both the wind system, as a key player in the generation of surface ocean waves, and the wave resource itself.

According to the UK Met Office climate wind data (http://www.metoffice.gov.uk/), the prevailing wind directions over the west region of Scotland lie between south and northwest for the majority of occasions, and the strongest winds nearly always blow from this range of directions. This is mainly attributed to the Atlantic depressions, which pass by the United Kingdom, and is considered the main cause of air mass movement over the region. Results of wind analysis by Corbel et al. (2007) revealed that 
the occurrence of strong south westerly winds at sites around the Scottish coasts is closely linked to the behaviour of the North Atlantic Oscillation (NAO).

Most of the long-term wind analysis research and studies focused on the use of winds as a renewable energy resource, i.e. wind power, e.g. Youm et al. (2005); Sinden (2007); Lindsey (2011); Olaofe and Folly (2012); Anastasiades and McSharry (2013). The target has mainly been to specify conditions and characteristics of windy regions and to test the feasibility of wind farm construction according to density function, height variability, wind energy potential, turbine distribution...etc.

The behaviour of waves is determined by the spectrum of the sea state, $S(f, \theta)$, which specifies how the wave energy is distributed in terms of frequency and direction (Longuet-Higgins 1957; Mollison 1994). However, many models of the spectrum of wave measured at a certain point are widely-used regardless the wave direction. Generally speaking, there are two main types of these wave spectra: the mono-parameter spectrum (e.g. Pierson and Moskowitz 1964) and the multi-parameter spectrum (e.g. Bretschneider 1959; Hasselmann et al. 1973; Ochi-Hubble 1976). The spectrum type is determined based on the required number of the input parameters. Wind and wave properties in the shelf regions of the Atlantic Ocean, including the coasts of Scotland have been previously studied (e.g. Woolf and Challenor 2002; Wolf and Woolf 2005; Weisse and von Storch 2010).

Trends and cycles for climatological parameters, hydrography and fish catch have been investigated for long-term data in different regions worldwide, e.g. Maiyza 1984; Fedrouich 1985; Baumgartner et al. 1992; Kawasaki 1994; Levitus 1995; Hylen 2002; Klyashtorin and Lyubushin 2007; Sundby and Drinkwater 2007; Maiyza and Kamel 2009; 2010; Maiyza et al. 2011; Said et al. 2012; El-Geziry et al. 2013. Moreover, from a the behavioural point of view, long-term variations in winds have been previously investigated in the south-eastern Mediterranean Sea region (El-Geziry et al. 2013). All these studies proved the cyclic nature and strengthened the concept of oscillations of the examined parameters. The cycle of those oscillations have periods that may extend to centuries.

To the author's knowledge, the long-term trends of variations in the wind-wave climatology over the west region of Scotland have not been previously examined from a behavioural trend point of view. The present paper aims at drawing the possible long-term trends of winds and ten surface wave parameters over the west region of Scotland, using the quadratic regression approach. For those who work in the wave energy field, year-to -year and long term climatic variability are especially important for estimating the life time extremes that a structure will experience (Mollison 1994).

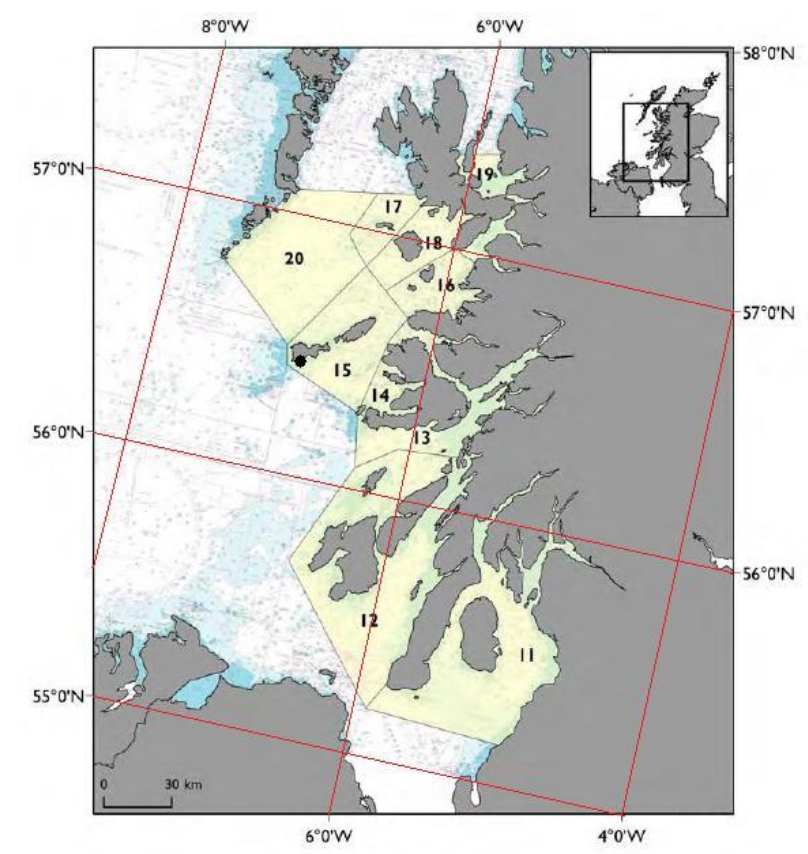

Fig .1. Map of the west region of Scotland showing the location of Tiree meteorological station (Adapted from Speedie et al., 2009)

\section{DATA AND METHOD OF ANALYSIS}

The selected data set of wind vectors (speed and direction) covers 38 years (January 1973 - December 2010) based on hourly records over the period of investigation.

This is obtained from Tiree meteorological station $\left(56^{\circ}\right.$ $30.00^{\prime} \mathrm{N} ; 6^{\circ} 52.98^{\prime} \mathrm{W}$; Fig. 1) placed at an elevation of $9 \mathrm{~m}$ above the Mean Sea Level (MSL) (http://gis.ncdc.noaa.gov/map/viewer/\#app=cdo). This station, facing an open sea region, is used as a representative meteorological point for the whole western region of interest.

The dominant wind directions over the period of investigation have been specified through the calculation of the percentage of wind occurrence frequency. 
The mean monthly wind speed (MMWS; mean for specific month every year) for the four most dominant wind components over the 38-year data set and the monthly mean speed ( $\mathrm{Wm}$; mean for specific month of all years) for every month in the whole data set are calculated. The deviation from the monthly mean $(\Delta \mathrm{W})$ is computed on monthly basis in order to express the monthly wind anomaly (MWA), using the following equation:

$$
\Delta W \equiv M W A=M M W S-W_{m}
$$

The general trend of the monthly variation in the MWA is examined, using the quadratic regression approach. The specific years of the lowest and highest calculated MWA are determined using the first derivative concept for the generated equations.

The available wind data and the location of Tiree meteorological station satisfy the assumptions of Pierson and Moskowitz (1964):

- North Atlantic data, specified on the sea state as a Fully Developed Sea (FDS)

- Deep water

- Unlimited fetch

- Unidirectional sea, and

- No swell

Therefore, the Pierson-Moskowitz spectrum model has been applied in the present research. The spectral function of the spectrum takes the form:

$$
S(\omega)=\frac{\alpha}{\omega^{5}} g^{2} e^{-\beta\left(\frac{\omega_{o}}{\omega}\right)^{4}}
$$

Where, $S(\omega)$ is the wave spectral density function (m2s), $\alpha=0.0081, \omega$ is the wave angular frequency $(\mathrm{rad} / \mathrm{s}), \mathrm{g}$ is the acceleration of Earth's gravity (9.81 $\mathrm{m} / \mathrm{s} 2$ ), $\beta=0.74$ and $\omega o=\mathrm{g} / \mathrm{U} 19.5$ (rad/s). U19.5 is the wind speed $(\mathrm{m} / \mathrm{s})$ at a height of $19.5 \mathrm{~m}$ above the MSL; U19.5 = 1.075 U10. U10 is the measured wind speed $(\mathrm{m} / \mathrm{s})$ at a height of $10 \mathrm{~m}$ above the MSL. In the present work, $\mathrm{U} 10$ is the wind speed directly recorded by Tiree meteorological station.

The wave peak frequency ( $\mathrm{rad} / \mathrm{s})$ and peak speed $(\mathrm{m} / \mathrm{s})$ of the Pierson-Moskowitz spectrum are, respectively, calculated by the Equations: $\omega_{p}=0.877(g / U 19.5)=0.877 \omega_{\circ}$

$\mathrm{cp}=\mathrm{g} / \omega \mathrm{p}$

The significant wave height $(\mathrm{m})$ calculated from the Pierson-Moskowitz spectrum is

$H_{s}=0.21\left(\frac{U_{19.5}^{2}}{g}\right)$

and the wave peak period (s) is

$T_{p}=\frac{2 \pi}{\omega_{p}}=7.14\left(\frac{U_{19.5}}{g}\right)$

In order to get the wave angular frequency to build-up the Pierson-Moskowitz spectrum for the present research, the satisfied FDS condition enabled to derive both the corrected wind speed (UA; $\mathrm{m} / \mathrm{s}$ ) and the wave period $(T ; s)$ using the following Equations (Holmes 2001):

$U_{A}=0.71 U_{10}^{1.23}$

$\mathrm{T}=0.83 \mathrm{UA}$

The wave energy (E; J) (Holthuijsen 2007) and the wave power (P; W/m2) (Phillips 1977) are calculated using the two following Equations, respectively:

$E=\frac{1}{8} \rho g H_{s}^{2}$

Where $E$ is the wave energy $\rho$ is the ocean water density $1025 \mathrm{~kg} / \mathrm{m} 3$

$P=E C_{g}$

Where, $\mathrm{P}$ is the wave power $\mathrm{Cg}$ is the wave group velocity $(\mathrm{m} / \mathrm{s})$, calculated as the half peak wave celerity for the present deep water wave status. The general trends of the long-term variations of the different wave parameters off the western coasts of Scotland have been produced using the quadratic regression approach. These parameters are the wave frequency, the wave angular frequency, the peak angular frequency, the wave spectral density, the significant wave height, the peak period, both the peak and group velocities and lastly the wave energy and the wave power. 


\section{RESULTS}

\section{Hourly Wind-Wave climatology}

The raw data set downloaded directly from the meteorological site consists of 397340 hourly observations. This exceeds the supposed record of observation, 333096 hours, for the 38 years of study. This data excess is mainly attributed to data repetition and to the extra 10,20 and 50 minutes of records in some months. Accordingly, the initial data set has been filtered and the final data set used for the present analysis has been set up to consist of 323866 hourly records of both wind speed and wind direction. This represents $97.23 \%$ of availability, with 9230 records $(2.77 \%)$ missed. However, statistically speaking, these missed records do not affect the data quality to proceed for the proposed investigation. Over the period of investigation, the hourly wind speed varied between calm $(0 \mathrm{~m} / \mathrm{s})$ and $38.89 \mathrm{~m} / \mathrm{s}$ with an average of $7.34 \mathrm{~m} / \mathrm{s}$ over the period of investigation. Moreover, 12 wind speed classes have been specified as shown in Table (1) and their percentage of occurrence has been figured out in Figure (2). While the dominant speed interval over the study period was $>5: 10 \mathrm{~m} / \mathrm{s}$, with an occurrence of $41.25 \%$, the lowest speed interval was $>35: 40 \mathrm{~m} / \mathrm{s}$ with $0.0006 \%$.

Table 1. Hourly Wind Speed Classes

\begin{tabular}{|c|c|}
\hline Wind Speed Classes $(\mathrm{m} / \mathrm{s})$ & No. of Observations \\
\hline $0($ Calm $)$ & 3628 \\
\hline$>0: 5$ & 107312 \\
\hline$>5: 10$ & 137408 \\
\hline$>10: 15$ & 63083 \\
\hline$>15: 20$ & 11273 \\
\hline$>20: 25$ & 1071 \\
\hline$>25: 30$ & 83 \\
\hline$>30: 35$ & 6 \\
\hline$>35: 40$ & 2 \\
\hline Missed data & 9230 \\
\hline
\end{tabular}

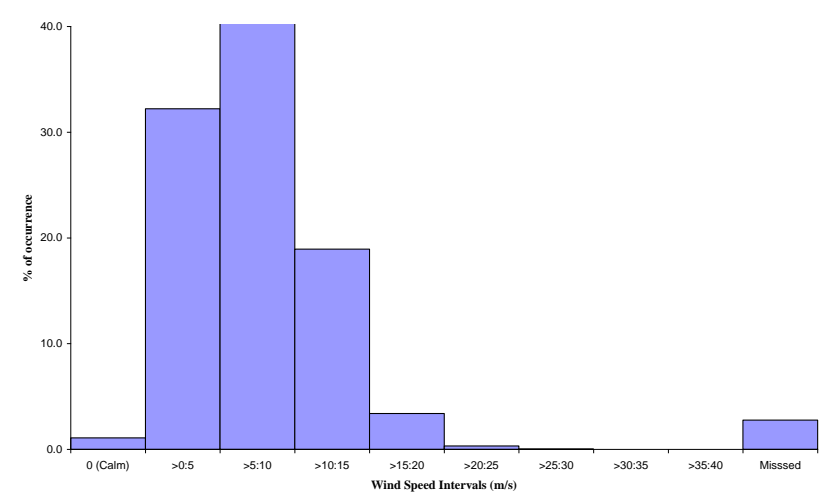

Fig .2. The percentage of occurrence of different wind speed intervals
The hourly statistics of the different wave parameters from January 1973 to December 2010 are shown in Table (2). The Pierson-Moskowitz wave spectrum for the present hourly wind speed is shown in Figure (3). Figure (4) shows the hourly significant wave height and hourly wave peak period calculated from the Pierson-Moskowitz spectrum.

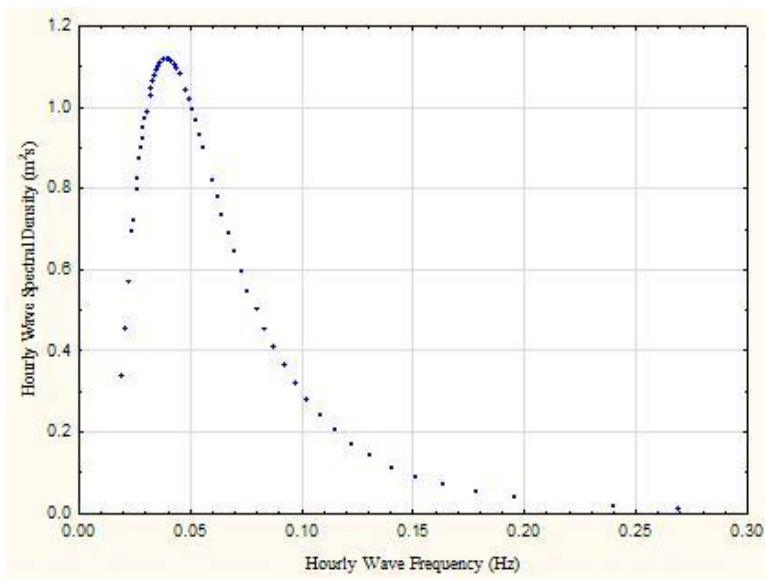

Fig .3. The FDS Pierson-Moskowitz spectrum off the western coasts of Scotland based on the hourly wind records

Table 2 . Hourly statistics of the different wave parameters

\begin{tabular}{|c|c|c|c|}
\hline & Minimum & Maximum & Mean \\
\hline $\begin{array}{l}U_{10}, \text { recorded wind speed, } \\
(\mathrm{m} / \mathrm{s})\end{array}$ & 0 & 38.89 & 7.34 \\
\hline $\begin{array}{l}U_{A}, \text { corrected wind speed, } \\
(\mathrm{m} / \mathrm{s})\end{array}$ & 0 & 64.0 & 8.5 \\
\hline T, wave period, (s) & 0 & 53.1 & 7.1 \\
\hline$f$, wave frequency, $(\mathrm{Hz})$ & 0.0187 & 0.280 & 0.250 \\
\hline $\begin{array}{c}\omega, \text { wave angular frequency, } \\
(\mathrm{rad} / \mathrm{s})\end{array}$ & 0.1181 & 28.714 & 1.571 \\
\hline $\begin{array}{l}\mathrm{U}_{19.5}, \text { wind speed at } 19.5 \mathrm{~m} \\
\text { above MSL, }(\mathrm{m} / \mathrm{s})\end{array}$ & 0 & 41.8 & 7.8 \\
\hline $\begin{array}{c}\text { S }(\omega), \text { wave spectral density, } \\
\left(\mathrm{m}^{2} \mathrm{~s}\right)\end{array}$ & 0 & 1.122 & 0.189 \\
\hline $\begin{array}{c}\omega_{p}, \text { wave peak frequency, } \\
(\mathrm{rad} / \mathrm{s})\end{array}$ & 0.2057 & 17.903 & 1.577 \\
\hline $\mathrm{C}_{\mathrm{p}}$, wave peak speed, $(\mathrm{m} / \mathrm{s})$ & 0 & 47.6 & 8.9 \\
\hline $\mathrm{H}_{\mathrm{s}}$, significant wave height, $(\mathrm{m})$ & 0 & 37.4 & 1.7 \\
\hline $\mathrm{T}_{\mathrm{p}}$, wave peak period, $(\mathrm{s})$ & 0 & 30.4 & 5.7 \\
\hline $\mathrm{E}$, wave energy, $(\mathrm{J})$ & 0 & 1759948 & 7467.19 \\
\hline $\mathrm{C}_{\mathrm{g}}$, wave group velcoity, $(\mathrm{m} / \mathrm{s})$ & 0 & 23.7 & 4.4 \\
\hline $\mathrm{P}$, wave power, $\left(\mathrm{W} / \mathrm{m}^{2}\right)$ & 0 & 41941970 & 64319.28 \\
\hline
\end{tabular}




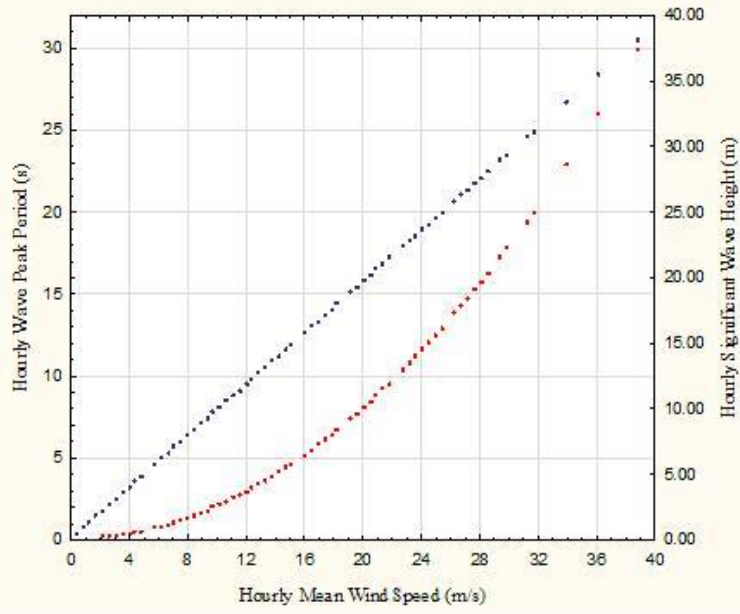

Fig .4. Significant wave height and period at the peak of the spectrum of FDS calculated from the Pierson-Moskowitz spectrum using Equations (5 and 6)

\section{Dominant Wind Directions}

The dominant wind directions in the present study have been determined using the percentage of wind occurrence frequency for the main 16 wind directions. Table (3) shows this percentage in a descending order. From this Table, the four major dominant winds during the period of investigation were the southern $(\mathrm{S})$, the western (W), the south-western (SW) and the north-western (NW) winds.

This agrees with the general climatology of the wind direction prepared by the UK Met Office for the region of west of Scotland. The calm wind $(0 \mathrm{~m} / \mathrm{s})$ represented $1.09 \%$ of the recorded wind data, i.e. 3628 hourly records.

\section{A. Mean Monthly Wind speed (MMWS)}

The mean monthly wind speed (MMWS) is one of the most important parameters in the wind profile of any given site.

Figure (5) shows the histogram of the MMWS variations. In Table (4), Vmin, Vmax and MMWS are the mean monthly minimum wind speed, mean monthly maximum wind speed and the mean monthly wind speed, respectively. It can be seen that the highest Vmax as well as the maximum MMWS occur during the three months of the winter season: January, February and December.

This reveals that these months might have the potential of recording the highest amount of exploited wave energy in the area of investigation.

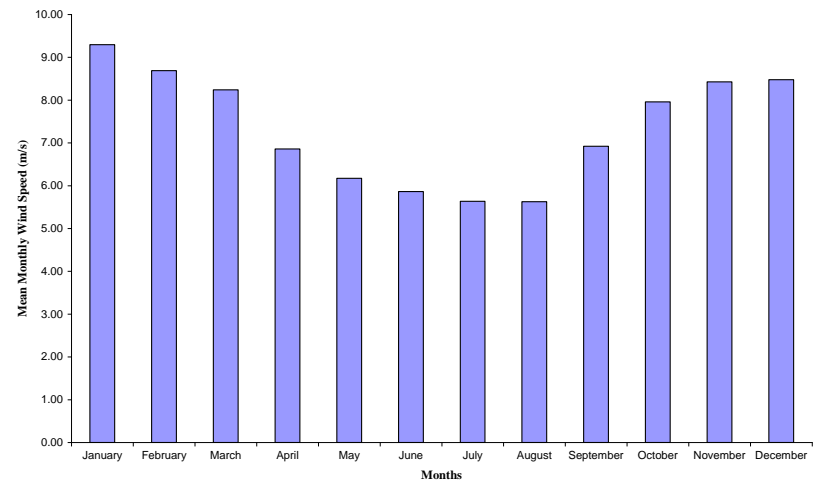

Fig .5. Histogram of the Mean Monthly Wind Speed (MMWS) over the study period

Table 3. Percentage of occurrence frequency of wind directions

\begin{tabular}{|c|c|c|}
\hline Wind Direction & No. of hourly records & $\begin{array}{c}\% \text { of occurrence } \\
\text { frequency }\end{array}$ \\
\hline$S$ & 34742 & 10.43 \\
\hline W & 33310 & 10.00 \\
\hline SW & 31777 & 9.54 \\
\hline NW & 28646 & 8.60 \\
\hline SSW & 25715 & 7.72 \\
\hline SE & 24216 & 7.27 \\
\hline WSW & 21784 & 6.54 \\
\hline SSE & 21784 & 6.54 \\
\hline NWN & 17421 & 5.23 \\
\hline WNW & 16655 & 5.00 \\
\hline ESE & 16055 & 4.82 \\
\hline$E$ & 10926 & 3.28 \\
\hline NE & 10659 & 3.20 \\
\hline NNE & 9560 & 2.87 \\
\hline $\mathrm{N}$ & 9327 & 2.80 \\
\hline EEN & 7661 & 2.30 \\
\hline $\begin{array}{c}\text { Direction } \\
\text { Records }\end{array}$ & 320238 & 96.14 \\
\hline $\begin{array}{c}\text { Calm wind }(0 \\
\mathrm{m} / \mathrm{s})\end{array}$ & 3628 & 1.09 \\
\hline Missed Records & 9230 & 2.77 \\
\hline
\end{tabular}


Table 4. Minimum, maximum and mean monthly wind speeds over the study period

\begin{tabular}{|c|c|c|c|}
\hline & $\mathrm{V}_{\min }(\mathrm{m} / \mathrm{s})$ & $\begin{array}{c}\mathrm{V}_{\max } \\
(\mathrm{m} / \mathrm{s})\end{array}$ & MMWS $((\mathrm{m} / \mathrm{s})$ \\
\hline January & 6.24 & 12.36 & 9.29 \\
\hline February & 5.59 & 12.07 & 8.69 \\
\hline March & 5.93 & 10.57 & 8.24 \\
\hline April & 4.17 & 8.62 & 6.86 \\
\hline May & 4.11 & 8.62 & 6.17 \\
\hline June & 4.15 & 7.75 & 5.86 \\
\hline July & 4.29 & 7.39 & 5.63 \\
\hline August & 3.93 & 7.20 & 5.63 \\
\hline September & 5.44 & 8.77 & 6.92 \\
\hline October & 5.59 & 10.19 & 7.96 \\
\hline November & 6.33 & 10.54 & 8.43 \\
\hline December & 5.97 & 11.58 & 8.48 \\
\hline
\end{tabular}

Over the period of investigation, the quadratic regression of the MMWS has a parabolic form (Fig. 6), which reflects an apparent cyclic trend in the changes of the MMWS over the investigated area. A longer time series of recorded wind data will be advantageous to confirm with more clarification this cyclic behaviour, i.e. cycle length and points of cyclereverse. The quadratic regression model is represented by the Equation:

MMWS $=4.04 E-06 x^{2}-0.0035 x+7.8665$

The month of the minimum MMWS occurrence is determined to be January 2009. The resultant parabola shows a general trend of decrease from January 1973 to January 2009 with a rate of 0.0017 $\mathrm{ms}-1 /$ month $(0.0204 \mathrm{~ms}-1 / \mathrm{yr})$, followed by a very slow gradual increase up to the end of the investigated period with a rate of $0.00008 \mathrm{~ms}-1 /$ month $(0.00096$ $\mathrm{ms}-1 / \mathrm{yr})$.

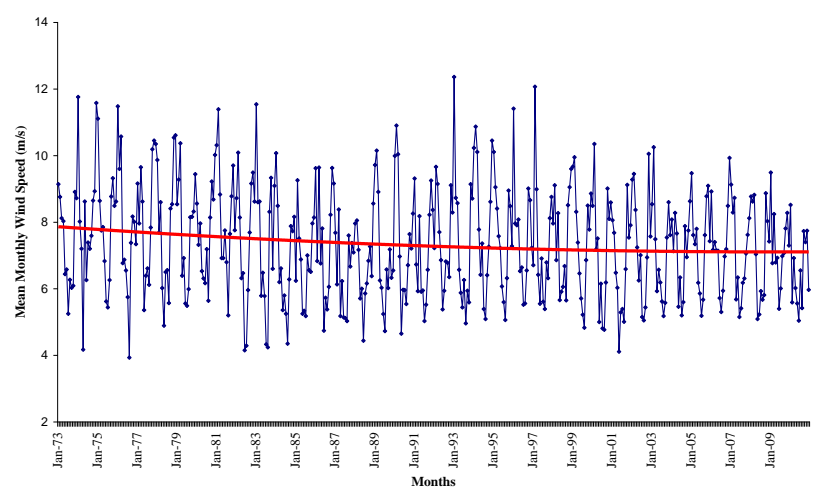

Fig .6. Quadratic regression model of the MMWS over the study period

\section{B. The Four Major Dominant Wind Components}

In the following discussion, the trend of variations of the four major main dominant components over the region of interest will be discussed. This will be presented according to the descending percentage of occurrence frequency (Table 3).

\section{The Southern Wind Component (S)}

Wind blowing from the south dominates the region of investigation. Over 38 years of hourly records, the southern wind represented $10.43 \%$ of occurrence. The quadratic trend of the southern variations is mathematically expressed by:

S-MWA $=1.6287 \mathrm{E}-06 \times 2-0.0006 x+0.0132$

This results in a parabolic cyclic variation (Fig. 7) with a minimum occurrence of the S-MWA in April 1988. A general decrease $(0.0003 \mathrm{~ms}-1 /$ month; $0.0036 \mathrm{~ms}-1 / \mathrm{yr}$ ) occurred from January 1973 to April 1988 followed by a general increase $(0.00044$ $\mathrm{ms}-1 / \mathrm{month} ; 0.00528 \mathrm{~ms}-1 / \mathrm{yr}$ ) afterwards. The zero values of the S-MWA (points of intersection with the months' axis) occurred in November 1974 and September 2001.

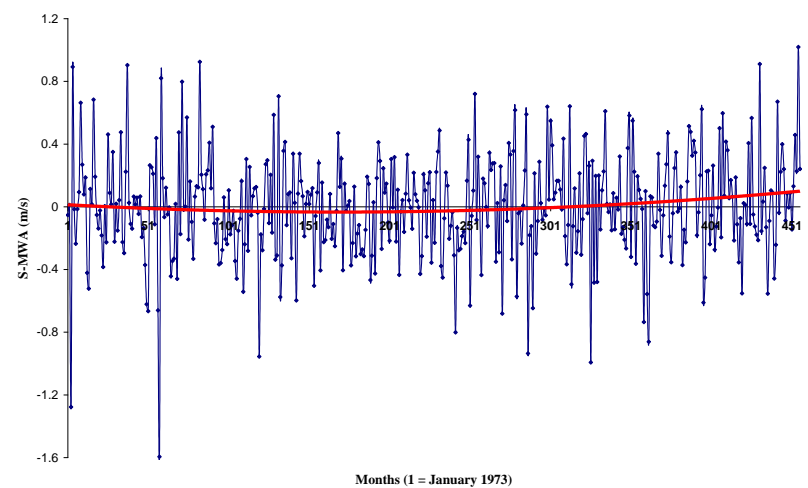

Fig .7. Quadratic trend of variation in the S-MWA over the period of investigation

\section{The Western Wind Component (W)}

Wind blowing from the west represented $10 \%$ of the recorded hourly data over the 38 years of investigation. In contrast to the south wind component, the quadratic regression model of the westerly MWA tends to produce a concave-down parabolic figure (Fig. 8), the maximum of which occurred in May 1995. There is an increasing rate from January 1973 to May 1995 (0.0003 ms-1/month; $0.0036 \mathrm{~ms}-1 / \mathrm{yr}$ ) followed by a slight decreasing rate of 
$0.0002 \mathrm{~ms}-1 /$ month $(-0.0024 \mathrm{~ms}-1 / \mathrm{yr})$ from May 1995 to December 2010.

The zero values of the W-MWA occurred in September 1982 and January 2008. The quadratic regression model of the W-MWA is mathematically represented by the following Equation:

W-MWA $=-1.1136 \mathrm{E}-06 \times 2+0.0006 x-0.0551$

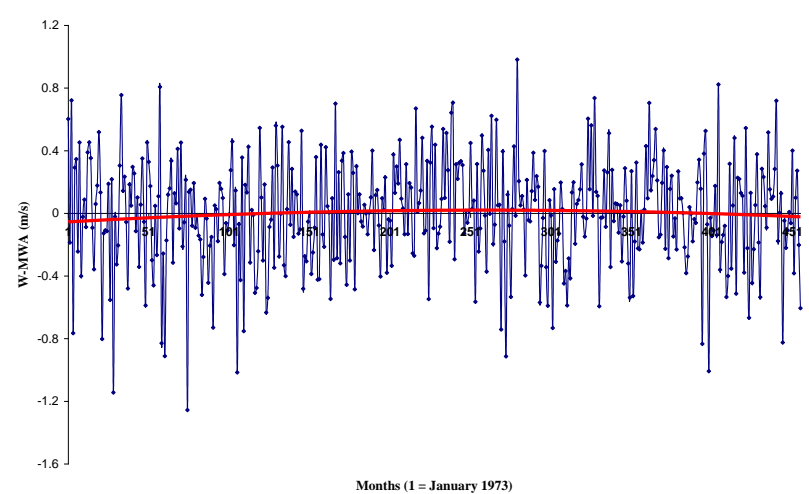

Fig .8. Quadratic trend of variation in the W-MWA over the period of investigation

\section{The South-West Wind Component (SW)}

The south-west wind component comes third in the frequent occurrence during the period of investigation, with $9.54 \%$. The quadratic regression of the SW-MWA (Fig. 9) reflects a parabolic form the minimum of which is out of the present data in hand: May 1969. The apparent segment from the resultant parabola of the SW-MWA is an increasing segment with a rate of $0.00022 \mathrm{~ms}-1 / \mathrm{month}$, i.e. $0.00264 \mathrm{~ms}-1 / \mathrm{yr}$ (Equation 14). The zero values of the SW-MWA occurred in September 1994 and January 1947.

SW-MWA $=4.9024 \mathrm{E}-07 \times 2+2.5313 \mathrm{E}-05 \times-0.0399$

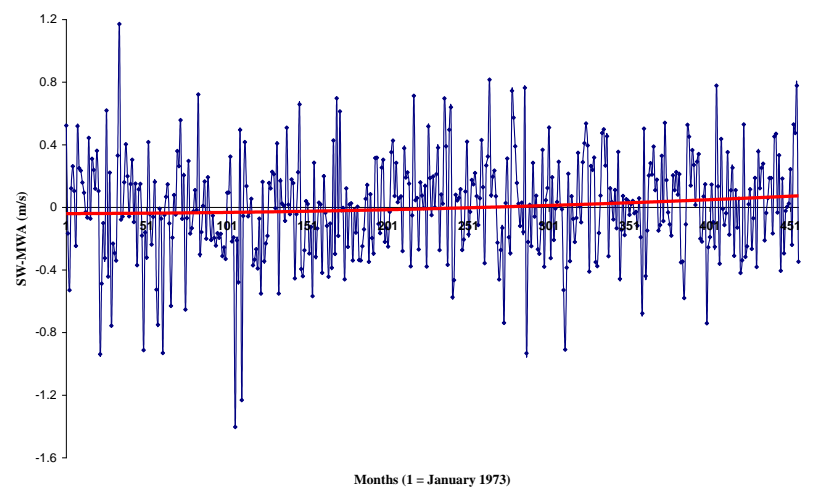

Fig .9. Quadratic trend of variation in the SW-MWA over the period of investigation

\section{The North-West Wind Component (NW)}

This wind component is the fourth dominant wind component over the study period with an $8.6 \%$ occurrence. The quadratic examination of changes of this monthly wind anomaly component (Fig. 10) reflects both an increasing rate and a decreasing rate over two successive time-interval segments. While the first is $0.011 \mathrm{~ms}-1 / \mathrm{month}(0.012 \mathrm{~ms}-1 / \mathrm{yr})$ from January 1973 to July 1994 , the second rate is $0.0017 \mathrm{~ms}-1 /$ month $(-0.0204 \mathrm{~ms}-1 / \mathrm{yr})$ from July 1994 onwards. This apparent trend of the NW wind component followed that of the westerly component shown above. The zero values of the NW-MWA occurred in September 1975 and April 2000. The quadratic model equation which represents the NWMAW is:

NW-MWA $=-1.6602 \mathrm{E}-06 \times 2+0.0006 \mathrm{x}-0.018$

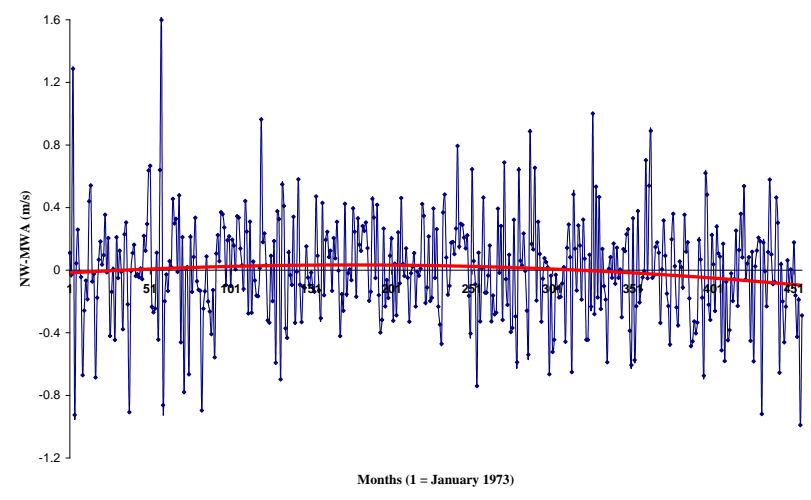

Fig .10. Quadratic trend of variation in the NW-MWA over the period of investigation

3. Quadratic Regression Models of the Different Wave Parameters

In order to describe the wave climate off the western coasts of Scotland, the long term changes in the ten mentioned wave parameters are considered.

The minimum mean monthly $\mathrm{S}(\omega)$ was $0.01 \mathrm{~m} 2 \mathrm{~s}$ and the maximum was $0.53 \mathrm{~m} 2 \mathrm{~s}$, with an average of 0.12 $\mathrm{m} 2 \mathrm{~s}$ over the study period. The mean monthly $f$ ranged from $0.08 \mathrm{~Hz}$ to $0.32 \mathrm{~Hz}$ with an average of $0.16 \mathrm{~Hz}$, and the mean monthly $\omega$ varied between $0.48 \mathrm{rad} / \mathrm{s}$ and $1.98 \mathrm{rad} / \mathrm{s}$ with an average of 0.98 $\mathrm{rad} / \mathrm{s}$ over the study period. The mean monthly Hs and $\mathrm{Tp}$ calculated from the mean monthly PiersonMoskowitz spectrum in the present study is shown in Figure (11). The mean monthly $\mathrm{Hs}$ ranged from 0.38 $\mathrm{m}$ to $3.78 \mathrm{~m}$ with an average of $1.40 \mathrm{~m}$, and the $\mathrm{Tp}$ 
varied between $3.07 \mathrm{~s}$ and $9.67 \mathrm{~s}$ with an average of $5.75 \mathrm{~s}$, over the study period.

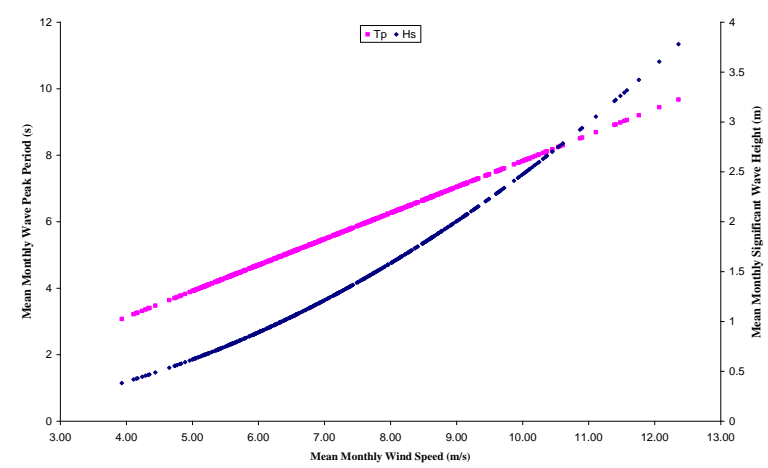

Fig .11. The mean monthly Hs and Tp of the mean monthly Pierson-Moskowitz spectrum over the study period

The examination of the long term trends of variations of the different wave parameters reveals that the mean monthly $f$ is in an inverse relationship to the mean monthly winds speed (MMWS), with a correlation factor of -0.96 . This is the same situation for both $\omega$ and $\omega p$. The latter varied between 0.65 $\mathrm{rad} / \mathrm{s}$ and $2.00 \mathrm{rad} / \mathrm{s}$, with an average of $1.14 \mathrm{rad} / \mathrm{s}$ over the study period. The general trends of the three frequencies are shown in Figures (12-14).

The mean monthly $f$ (MMf) is quadratically expressed by the Equation:

$M M f=-1 E-07 \times 2+1 E-04 x+0.1442$

This mathematically expresses a concave-down parabola, the increase rate of which is $0.018 \mathrm{Hzyr}-1$, with a maximum occurrence in August 2014.

The mean monthly $\omega(\mathrm{MM} \omega)$ tends to have the same parabolic form but with a maximum occurrence in August 2000, i.e. preceding that of the MMf by 14 years. This is expressed by the following Equation:

$\mathrm{MM \omega}=-9 \mathrm{E}-07 \times 2+0.0006 \mathrm{x}+0.9062$

This implies an initial increasing rate in the MMw of 0.003 rads- 1 yr- 1 from January 1973 to August 2000 followed by a decreasing rate of 0.001 rads-1yr- 1 afterwards.

The quadratic expression of variations in the mean monthly $\omega p$ (MM $\omega p)$ is:

$M M \omega p=-8 E-07 x 2+0.0006 x+1.0707$

The MMwp increased from January 1973 to March
2003 followed by a gradual decrease afterwards, with rates of 0.004 rads- $1 \mathrm{yr}-1$ and -0.02 rads- $1 \mathrm{yr}-1$, respectively.

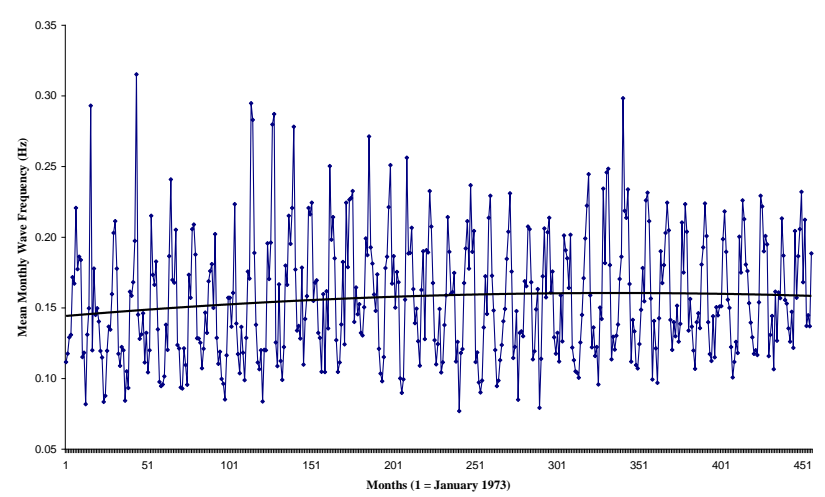

Fig .12. The mean monthly Hs and Tp of the mean monthly Pierson-Moskowitz spectrum over the study period

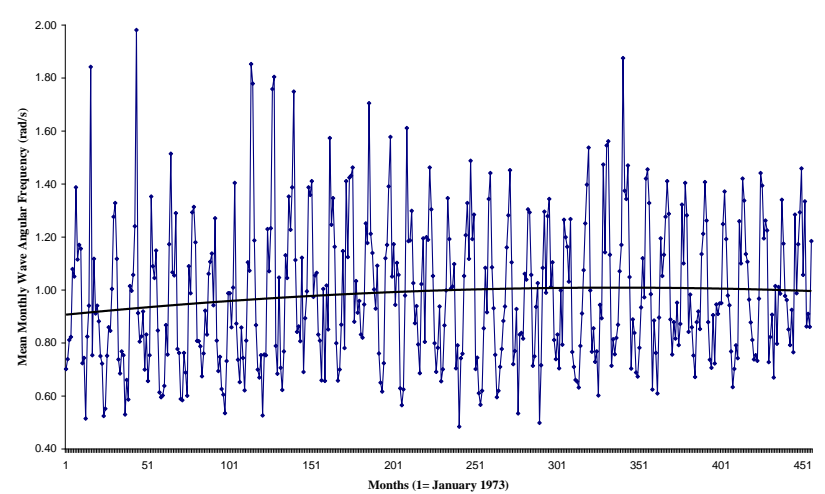

Fig .13. Quadratic trend of variation of the MMw over the period of investigation

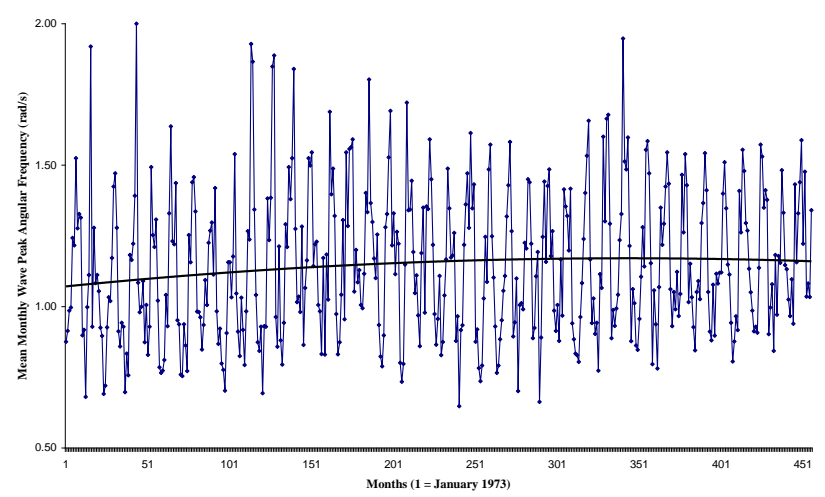

Fig .14. Quadratic trend of variation of the MMwp over the period of investigation

Over the period of investigation, the mean monthly wave spectral density, $\operatorname{MMS}(\omega)$, did not show any parabolic form or a cyclic behaviour. In contrast, a general decrease trend is more obvious for the $\operatorname{MMS}(\omega)$, with both the quadratic (Blue solid line) and 
linear (Red dashed-line) regressions almost superimposable (Fig. 15). While the first has a rate of $0.0018 \mathrm{~m} 2 \mathrm{syr}-1$ the second has a rate of -0.0012 m2syr-1. The correlation factor between the MMS $(\omega)$ and the MMWS is 0.98 . The quadratic regression model of the $\operatorname{MMS}(\omega)$ is given by the following Equation:

$\operatorname{MMS}(\omega)=1 \mathrm{E}-07 \times 2-0.0002 x+0.1515$

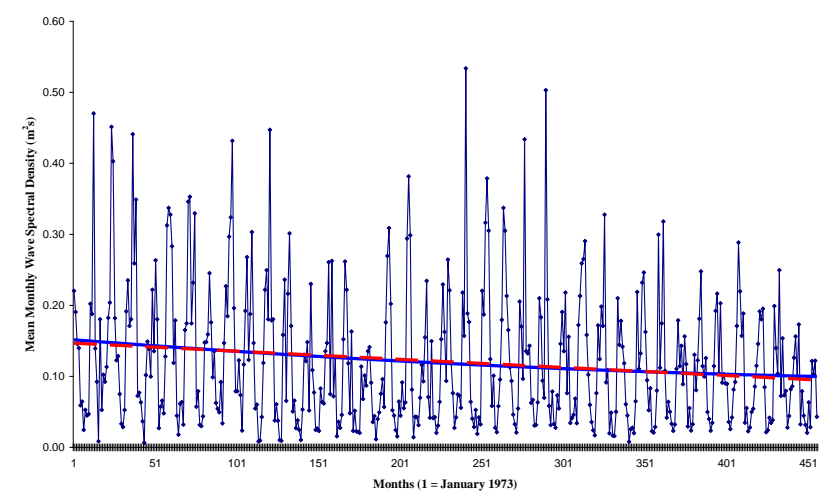

Fig .15. The mean monthly trends of variation of the MMS $(\omega)$ over the study period

During the study period, the mean monthly $\mathrm{Hs}$ (MMHs) was highly correlated to the MMWS, with a correlation factor of 0.98 . The long-term variations in the MMHs have a parabolic form (Fig. 16), which reflects a cyclic behaviour for this wave parameter. The MMHs decreased from January 1973 to May 2008, followed by a gradual increase afterwards. This is mathematically expressed by the following Equation:

$\mathrm{MMHs}=2 \mathrm{E}-06 \mathrm{x} 2-0.0017 \mathrm{x}+1.9563$

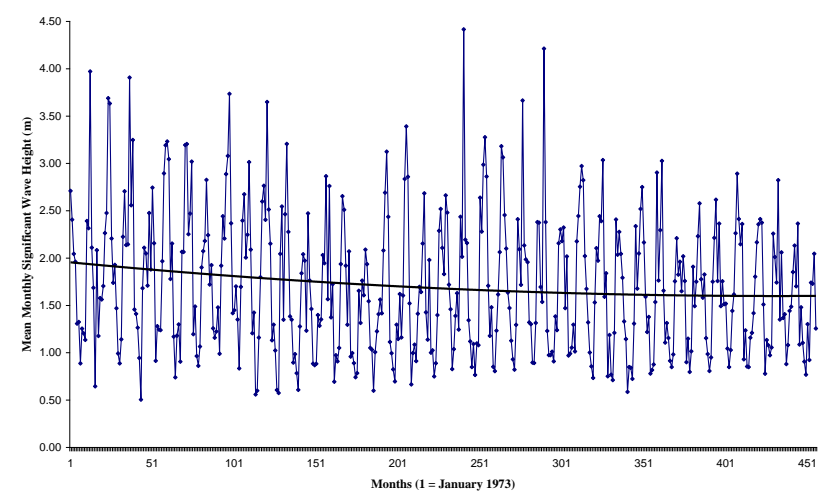

Fig .16. Quadratic trend of variation of the MMHs over the study period

The general trend of the mean monthly $\mathrm{Tp}$ (MMTp) tends to be cyclic (Fig. 17) with a quadratic expression as:

MMTp $=3 E-06 \times 2-0.00298 x+6.1694$

This reflects a large cycle with a minimum occurrence in May 2014, which is obviously out of the present data set and comes 6 years after the minimum occurrence of the MMHs. The MMTp is highly correlated to the MMWS, with a factor of 0.998 .

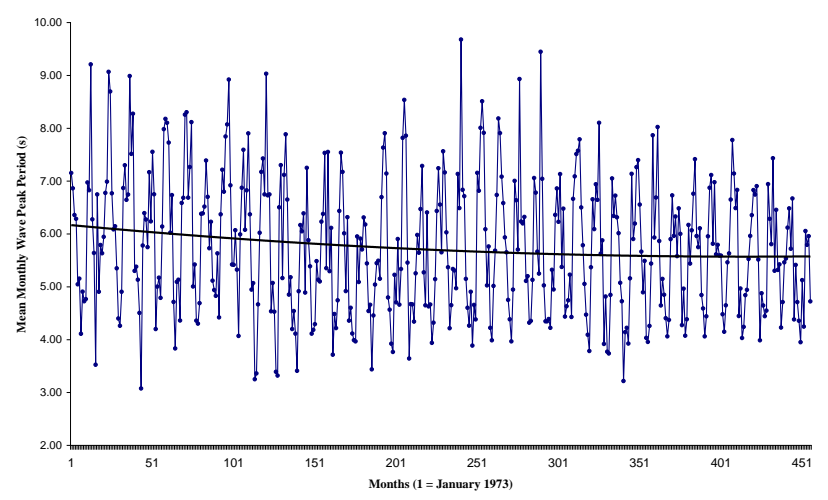

Fig .17. Quadratic trend of variation of the MMTp over the study period

Both the mean monthly $\mathrm{Cp}(\mathrm{MMCp})$ and $\mathrm{Cg}(\mathrm{MMCg})$ are positively correlated to the MMWS, with a factor of 0.998 , and both tend to have a cyclic behaviour of variations. While the minimum occurrence of the MMCp occurred in January 2010 (Fig. 18), one year after that of the MMWS, the minimum MMCg occurred in January 2003 (Fig. 19), six years before that of the MMWS. The Equation, which represents the variations of the MMCp is:

$M M C p=5 E-06 \times 2-0.00445 x+9.663$

The yearly rate of the MMCp decrease is 0.0265 ms1yr-1from January 1973 to January 2010, followed by a very slow rate of increase of $0.00066 \mathrm{~ms}-1 \mathrm{yr}-1$ afterwards. The MMCp varied from $4.91 \mathrm{~m} / \mathrm{s}$ to 15.15 $\mathrm{m} / \mathrm{s}$ with an average of $9 \mathrm{~m} / \mathrm{s}$ over the period of investigation.

The quadratic Equation, which represents the variations of the $\mathrm{MMC}_{\mathrm{g}}$ is:

$\mathrm{MMCg}=3 \mathrm{E}-06 \times 2-0.00217 \mathrm{x}+4.8287$

This results in two segments of variations (Fig. 19), the first of which has a rate of $-0.012 \mathrm{~ms}-1 \mathrm{yr}-1$ from January 1973 to January 2003, followed by an 
increasing segment with a rate of $0.0042 \mathrm{~ms}-1 \mathrm{yr}-1$. The $\mathrm{MMCg}$ ranged between $2.45 \mathrm{~m} / \mathrm{s}$ and $7.58 \mathrm{~m} / \mathrm{s}$, with an average of $4.5 \mathrm{~m} / \mathrm{s}$ over the study period.

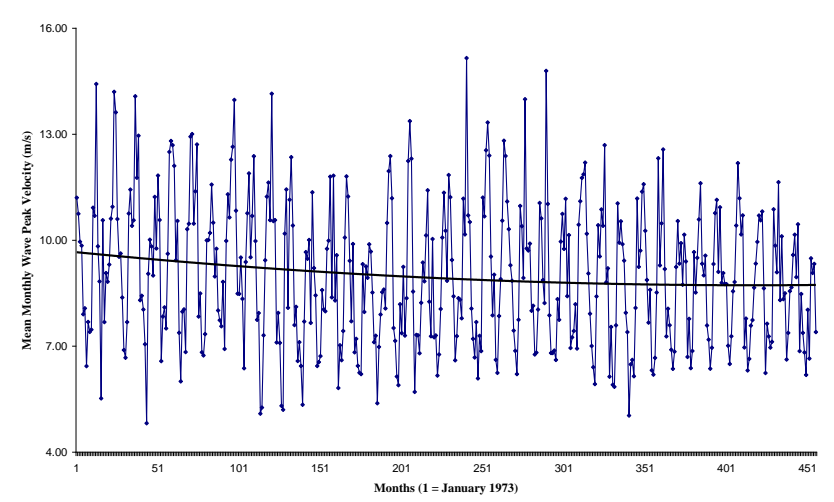

Fig .18. Quadratic trend of variation of the MMCp over the study period

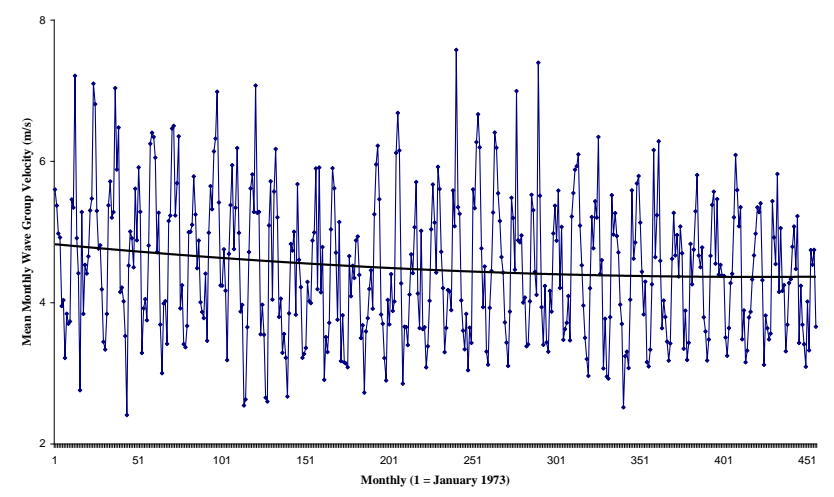

Fig .19. Quadratic trend of variation of the MMCg over the study period

Over the period of investigation, the quadratic regression of the mean monthly $E$ (MME) has a wellobserved parabolic form (Fig. 20), which reflects an apparent cyclic behaviour for the changes of the wave energy in the investigated area. The quadratic regression model is represented by the Equation:

$\mathrm{MME}=0.0172 \times 2-14.11602 \mathrm{x}+9536.2$

The MME varied from $183.49 \mathrm{~J}$ to $17951.93 \mathrm{~J}$ with an average of $2953.63 \mathrm{~J}$ over the study period. The minimum MME occurred in February 2007. The resultant parabola shows a general trend of decrease from January 1973 to February 2007 with a yearly rate of -160.5 Jyr-1. This is followed by an increase up to the end of the investigated period with a rate of 688.2 Jyr-1. The MME is highly correlated to the MMWS, with a correlation factor of 0.93 .

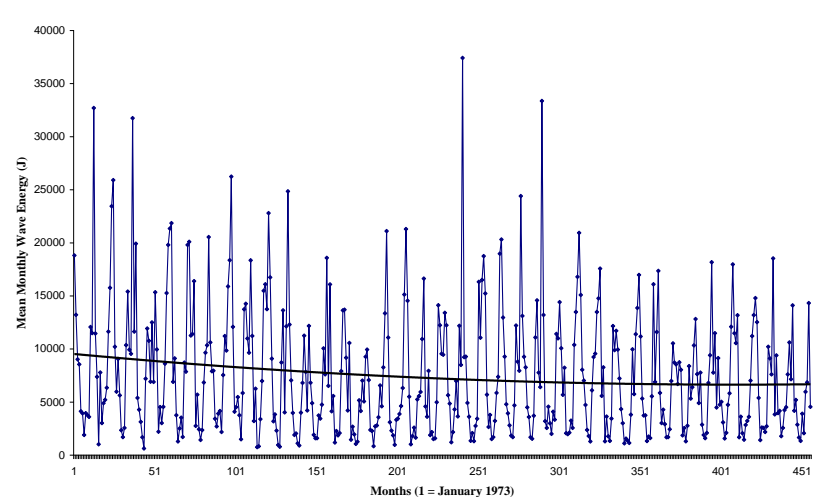

Fig .20. Quadratic trend of variation in the MME over the study period

The mean monthly $\mathrm{P}$ (MMP) is positively correlated to the MMWS. However, it appears to be the weakest wave parameter, among the investigated parameters, to be correlated to the MMWS having a correlation factor of 0.89 .

From January 1973 to December 2010, the MMP appeared to have a cyclic trend of variations (Fig. 21) with a minimum occurrence in May 2005. The two yearly rates of variations are $-952.86 \mathrm{Wm}-2 \mathrm{yr}-1$ from January 1973 to May 2005, and $163.44 \mathrm{Wm}-2 \mathrm{yr}-1$ from May 2005 to the end of the study period. The MMP varied from $450 \mathrm{~W} / \mathrm{m} 2$ to $135990.49 \mathrm{~W} / \mathrm{m} 2$ with an average of $15809.21 \mathrm{~W} / \mathrm{m} 2$ over the period of investigation. The representative Equation of these variations is:

$M M P=0.2049 \times 2-159.5203 x+86890$

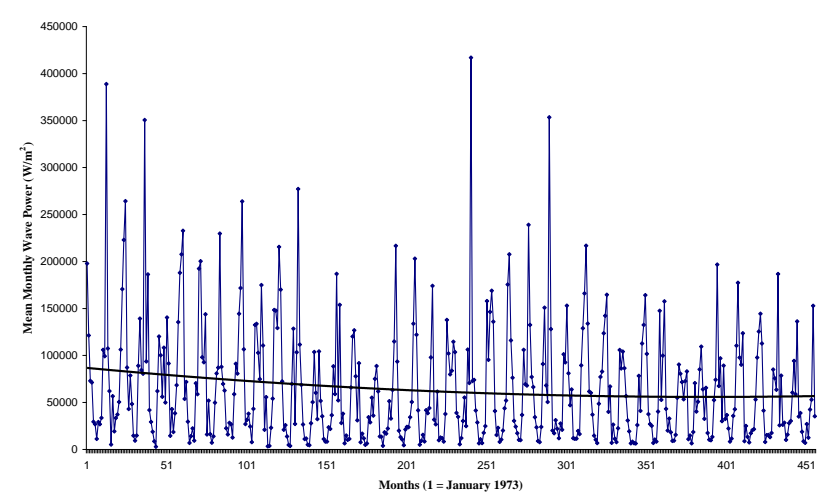

Fig .21. Quadratic trend of variation in the MMP over the study period

\section{DISCUSSION AND CONCLUSION}

To the author's knowledge, no work has dealt before with the changes in the long-term behaviour of windwave climatology over the west region of Scotland. 
The present study can be considered as an initial fair trial to get closer to the general behaviour of the major wind components and ten main wave parameters over this region.

The long-term variations of the wind-wave climatology have been examined using the quadratic regression model approach.

According to the percentage of occurrence frequency during the period January 1973-December 2010, the dominant wind components came from the south (S), the west (W), the southwest (SW) and the northwest (NW). All have the Atlantic Ocean origin and result mainly from the Atlantic depressions passing over the UK. This percentage computation agrees with the given information by the UK Met Office.

All over the period of investigation, the hourly wind speed varied between calm wind $(0 \mathrm{~m} / \mathrm{s})$ to a maximum of $38.89 \mathrm{~m} / \mathrm{s}$, with an hourly average speed of $7.34 \mathrm{~m} / \mathrm{s}$. Twelve hourly wind-classes have been specified for the area of investigation with the dominant speed interval $>5: 10 \mathrm{~m} / \mathrm{s}$ (occurrence of $41.259 \%$ ), and the lowest speed interval was $>35: 40$ $\mathrm{m} / \mathrm{s}$ with $0.0006 \%$.

The quadratic regression model of the mean monthly wind speed (MMWS) has a parabolic form, which reflects a cyclic behaviour of occurrence. From a quadratic point of view, the approach applied in this research to examine periodicity and cyclic behaviour, it can be deduced that the two major southern components have a common parabolic trend and the two major western components have another opposite common parabolic trend. Both the $S$ and the SW monthly winds anomalies have concave-up parabola with minimum MWA speed occurrence in April 1988 and May 1969, respectively. The later, minimum of the SW-MWA, is obviously out of the present in-hand set but meanwhile, reflects the possibility of existence of large cycles of occurrence for this wind component.

Both the W and the NW monthly wind anomaly speeds have concave-down parabola with maximum occurrence in May 1995 and July 1994, respectively.

From the calculations of the zero values of the different WMA parabolas, September has appeared a common month when the MWA half-cycle reverses its path, whether upward or downward, i.e. positively with an increasing rate or negatively with a decreasing rate.

The Pierson-Moskowitz spectrum conditions have been satisfied to apply the model in order to represent the wave climatology of the area of investigation. The spectrum has been previously discussed and applied in many regions, which satisfy the conditions of Pierson and Moskowitz (1964), e.g. Holmes (2001); Alves and Banner (2003); Sorensen (2006). Both significant wave height and wave peak period have been calculated form the PiersonMoskowitz spectrum and the resultant relationships with the MMWS and between the two parameters are in good agreement with the results of Harrison and Wallace (2005).

All wave frequencies are in an inverse correlation to the MMWS. All other wave parameters appear to be highly correlated to the mean monthly wind speed with correlation factors exceeding 0.95 except the wave power, which has a correlation factor of 0.89 .

In conclusion, the general behaviour of the dominant winds over the western region of Scotland tended to be cyclic. Two opposite cycles appeared to dominate: one for the southern components ( $S \& S W)$ and one for the western components (W \& NW). September was a month of cycle reverse for the MWA over the region. The general behaviour of the ten examined wave parameters over the western region of Scotland also tended to be cyclic.

A longer time series, than that presently used, will be advantageous in order to strengthen this outcome of this natural cyclic behaviour with more robust investigation. Longer time series will also enable to determine the cycle period for each of the investigated parameters. This concluded cyclic behaviour may positively impact on the engineering work within the wave energy resource off the western coasts of Scotland.

\section{REFERENCES}

[1] [Alves, J.H, Banner, M.L (2003) A Symptotic Limits for Fully Developed Wind Waves. Journal of Physical Oceanography 33: 1301-1323.

[2] Anastasiades, G. and McSharry, P.E. (2013) Extreme Value Analysis for Estimating 50 Year Return Wind Speeds from Reanalysis Data. Wind Energy 17(8): pp.1231-1245.

[3] Baumgartner, T.R., Soutar, A., and FerreiraBartrina V (1992) Reconstruction of the History of Pacific Sardine and Northern Pacific Anchovy 
Populations over the Past Two Millennia from Sediments of the Santa Barbara Basin. CalCOFI Reports 33: pp 24-40.

[4] Bretschneider, C.L. (1959) Wave Variability and Wave Spectra for Wind-Generated Gravity Waves U.S. Army Corps of Engineers, Beach Erosion Board, Technical Memorandum pp. 118: 192.

[5] Corbel G, Allen JT, Woolf DK, Gibb S (2007) Wind Trends in the Highlands and Islands of Scotland 1960-2004 and their Relation to the North Atlantic Oscillation. 19th Conference on Climate Variability and Change, San Antonio, Texas, January 2007.

[6] El-Geziry, T.M., Maiyza, I.A., Abdel-Hafez, S., Maiyza, Shl. and Kamel, M.S. (2013) Interannual Variability of the South-Eastern Mediterranean Catch and Its Relation to Hydrographical and Air-Temperature Anomalies". Journal of King Abdul-Aziz University: Marine Science 24 (1):43-54.

[7] El-Geziry, T.M., Maiyza, I.A., Maiyza, H.I. (2013) General Trend of Wind Anomalies in the SouthEastern Mediterranean Sea. Journal of King Abdul-Aziz University (JKAU), Marine Sciences 24 (2): pp 85-97.

[8] Fedrouich, L.A (1985) Regular Formation of Large Scale Temperature Anomalies of the Surface Layer in the Northern Pacific Ocean. Ph.D. Thesis, Moscow University.

[9] Harrison GP, Wallace AR (2005) "Sensitivity of Wave Energy to Climate Change. Energy Conversion" 20 (4):pp 870-877.

[10] Hasselmann, K., Barnett, T.P., Bouws, E. ET AL (1973) Measurements of Wind-Wave Growth and Swell Decay During the Joint North Sea Wave Project (JONSWAP). Report No.12, Deutches Hydrographisches Institute: p95.

[11] Holmes, P. (2001) Coastal Processes: Waves. In: "A Course in Coastal Defence Systems". Professional Development Programme: Coastal Infrastructure Design, Construction and Maintenance. St. Lucia, West Indies, 22p.

[12] Holthuijsen, L.H (2007) Linear Wave Theory
(Oceanic Waters). In: "Waves in Oceanic and Coastal Waters". Cambridge University Press, pp 106-143.

[13] Hylen, A. (2002) Fluctuations in Abundance of Northeast Arctic Cod During the 20th Century. ICES Marine Science Symposia: 534-550.

[14] Kawasaki, T. (1994) A Decade of the Regime Shift of Small Pelagics. Bulletin of the Japanese Society of Fisheries Oceanography 58: pp 321333.

[15] Klyashtorin, L.B, and Lyubushin, A.A (2007) Cyclic Climate Changes and Fish Reproductivity. Editors: Gary D. Sharp. VNIRO Publishing, Moscow.

[16] Levitus, S. (1995) Interannual to Decadal Scale Variability of the World Ocean. IAPSO XXI General Assembly, Honolulu, Hawaii, USA, August 5-12, 1995.

[17] Lindsey DT (2011) "A High Wind Statistical Prediction Model for the Northern Front Range of Colorado". National Weather Association, Electronic Journal of Operational Meteorology, 2011-EJ03.

[18] Longuet-Higgins, M.S (1957) The Statistical Analysis of a Random Moving Surface. Philosophical Transactions of the Royal Society of London, Series A: Mathematical and Physical Sciences 249 (966): pp321-387.

[19] Maiyza, I.A. and Kamel, M.S. (2009) Climatological Trend of Sea Surface Temperature Anomalies in the South Eastern Mediterranean Sea. Journal of King Abdul-Aziz University: Marine Science 20: 59-66.

[20] Maiyza, I.A and Kamel, M.S. (2010) Climatological Trend of Sea Surface Salinity anomalies in the South Eastern Mediterranean Sea. Journal of King Abdul-Aziz University: Marine Science 21(2): 63-72.

[21] Maiyza, I.A. (1984) Long -Term Variation of Water Temperature in the Eastern Part of the Mediterranean Sea, Ph. D. Thesis, Moscow University.

[22] Maiyza, I.A, El-Geziry, T.M, Maiyza, H.I. and 
Kamel, M.S (2011) Climatological Trend of Air Temperature Anomalies in the South-Eastern Mediterranean Sea. Journal of King Abdul-Aziz University: Marine Science 22 (2): 55-65.

[23] Mollison, D. (1994) Assessing the Wave Energy Resource. In: Statistics for Environment 2. Barnett and Turkman Eds. Wiley press, pp 205220.

[24] Ochi, M.K. and Hubble, E.N. (1976) SixParameter Wave Spectra. In: Coastal Engineering, pp 301-328.

[25] Olaofe, Z.O. and Folly, K.A. (2012) Statistical Analysis of the Wind Resources at Darling for Energy Production. International Journal of Renewable Energy Research 2 (2): pp 250-261.

[26] Phillips, O.M. (1977) The Dynamics of the Upper Ocean (2nd ed.). Cambridge University Press.

[27] Pierson ,W.J. and Moskowitz, L. (1964) A Proposed Spectral form for Fully Developed Wind Seas Based on the Similarity Theory of A. A. Kitaigorodskii. Journal of Geophysical Research 69: pp 5181-5190.

[28] Said, M.A, El-Geziry, T.M, Radwan, A.A (2012) Long-Term Trends of Extreme Climate Events over Alexandria Region, Egypt. International Conference on "Land-Sea Interactions in the Coastal Zone" Jounieh - Lebanon, 06-08 November 2012: pp 286-293.

[29] Sinden, G. (2007) Characteristics of the UK Wind Resource: Long-Term Patterns and Relationship to Electricity Demand. Energy
Policy 35 (1): 112-127.

[30] Sorensen, R.M. (2006) Wind-Generated Waves. In: "Basic Coastal Engineering. Springer", pp: 157-194.

[31] Speedie, C.D, Johnson, L.A. and Witt, M.J (2009) Basking Shark Hotspots on the West Coast of Scotland: Key sites, "Threats and Implications for Conservation of the Species". Commissioned Report 339: 58p.

[32] Sundby, S. And Drinkwater, K. (2007) On the Mechanisms Behind Salinity Anomaly Signal of the Northern North Atlanti. Progress in Oceanography 73: pp190-202.

[33] Youm, I., Sarr, J., Sall, M., Ndiaye, A. and Kane, M.M (2005) "Analysis of Wind Data and Wind Energy Potential along the Northern Coast of Senegal". La Revue des Energies Renouvelables 8: pp $95-108$.

[34] Woolf ,D.K, and Challenor, P.G (2002) Variability and Predictability of the North Atlantic Wave Climate. Journal of Geophysical research 107 (C10): doi: 10.1029/2001JC001124, p 14.

[35] Wolf, J. and Woolf, D.K. (2005) Waves and Climate Change in the Sea of the Hebrides. Proceedings of the 15th International Offshore and Polar Engineering Conference, Seoul, Korea, June 19-24, 2005: pp 100-107.

[36] Weisse, R. and Storch, V. H. (2010) Marine Climate and Climate Change. Springer Praxis, $p$ 219. 